\title{
Brownfield management opportunities to reduce the back pressure effects on the gas wells
}

\author{
Dan-Paul Stefanescu, ${ }^{1, *}$, and Diana-Andreea Lupu $^{2}$ \\ ${ }^{1}$ Lucian Blaga University of Sibiu, Faculty of Engineering, 4 E.Cioran, Sibiu, Romania \\ ${ }^{1}$ Exploration-Production Division, SNGN Romgaz SA, P-ta I.C.Motas 4, Medias, Romania \\ ${ }^{2}$ Stimulation-Rehabilitation Production Department, E\&P Division, SNGN Romgaz SA, P-ta \\ I.C.Motas 4, Medias, Romania
}

\begin{abstract}
Gas mature fields are associated with challenges to optimize the hydrocarbon flow from reservoir to the sales point in a cost effective manner due to declining well productivity. Laslau Mare field is a mature gas field in Transylvanian basin (Mures County) developed in 1970s and is producing $\sim 99 \%$ methane with low water-gas ratio. As any brown field, the state of depleted reservoir will generate several constraints for gas flow from formation to surface facilities and further to delivery point. During the exploitation has been observed that the operation conditions are facing with unstable pressure in the system due to low demand. Therefore, the back pressure effect will affect the wells in terms of inability to unload the bottomhole accumulated liquids and the reservoir will suffer a higher pressure drawdown. The best fit-for-purpose solution to overcome the above challenges is represented by installation of group compressor. Laslau Mare field has 3 group compressors running and shows positive results, especially when external pressure fluctuates continuously. This paper explain the challenges seen in 2016 in Laslau Mare field with back pressure effects and how the compression overcome them, and also other solutions that should be considered to optimize the well production.
\end{abstract}

\section{Introduction}

Gas fields from Transylvanian Basin have an advanced state of depletion considering the reservoir conditions after more than 50 years of exploitation and the intensive approach in terms of production. During exploitation, it has been found that is necessary to operate the fields in a rational and efficient manner in order to achieve attractive recovery factors. Rehabilitation concept has been developed which means a new approach of production management for field development or redevelopment plan.

Laslau Mare field is one of the field which is in a rehabilitation process subjected to many optimization projects executed in order to increase the recovery factor and to reduce the production decline.

Gas fields operation was faced throughout 2016 with many challenges, field operation conditions changed in terms of dynamic surface parameters represented by field pressure and

\footnotetext{
*Corresponding author: dan.stefanescu@romgaz.ro
} 
the national grid pressure at the sales point from Production System to National Transportation System.

Dynamic surface parameter variations plays an essential role on the wells performance and behaviour and influences the flow condition from porous-permeable formation to surface facilities.

Demand on natural gas market being at this moment an uncontrollable factor at national level has been dropped significantly during warm period of 2016. Uncertainty conditions on natural gas market demand have a secondary effect in field operation and obviously achieved production doesn't match with forecasted production.

Extending recovery factor by implementing rehabilitation projects involves those technical and economical solutions that can improve the productive performance of the reservoir and to face all challenges caused by external factor.

These technical and economic solution must target both improving productive performance of the reservoir and gas production infrastructure.

\section{Problem definition. Field challenges}

Laslau Mare field management faced during 2016 with high external pressure causing high impact in production and reservoir backpressure causing liquid loading.

The reason of higher field pressure is mainly due to higher sales pressure and/or Filitelnic/Tigmandru compression stations don't work at full capacity. Filitelnic and Tigmandru compression station are located at the interference point of productiontransportation system and are used to increase discharged pressure into network system.

It it has been observed during operation period there are different malfunctions in the system which could generate local pressure drops and is even more accentuated by reservoir pressure depletion and pipeline pressure drops. The flow gas through pipelines with different lengths and diameters is introducing a new pressure drop in the system which will led to increased production losses.

Jones 'Gas inflow performance relationship (IPR) equation characterized the pressure losses and it is very useful for gas reservoir exploitation design:

$$
\begin{gathered}
p_{r}^{2}-p_{w f s}^{2}=a \cdot Q_{g}^{2}+b \cdot Q \\
A O F P=\frac{b \pm \sqrt{b^{2}+4 a\left(p_{r}^{2}\right)}}{2 a} \\
a=\frac{3.16 \cdot 10^{-12} \beta \gamma_{g} T Z}{h_{p}^{2} r_{w}} \\
b=\frac{1.424 \cdot 10^{3} \mu T Z\left[\ln \left(0.472 \frac{r_{e}}{r_{w}}\right)\right]+S}{k h}
\end{gathered}
$$

where:

AOFP $=$ Absolute Open Flow Potential

$\mathrm{Q}=$ gas flow rate $[\mathrm{mcf} / \mathrm{d}]$

$\mathrm{a}=$ turbulence term

$\mathrm{b}=$ Darcy flow term

$\mathrm{p}_{\mathrm{r}}=$ reservoir pressure [psia]

$\mathrm{p}_{\mathrm{wfs}}=$ sandface flowing bottomhole pressure [psia]

$\beta=$ turbulence coefficient $\left[\mathrm{ft}^{-1}\right]$ 
$\gamma \mathrm{g}=$ gas specific gravity [dimesionless]

$\mathrm{Z}=$ supercompressibility [dimensionless]

$\mu=$ viscosity $[\mathrm{cP}]$

$\mathrm{re}=$ drainage radius $[\mathrm{ft}]$

$\mathrm{rw}=$ wellbore radius $[\mathrm{ft}]$

$\mathrm{S}=$ skin factor [dimesionless]

$\mathrm{hp}=$ perforated interval $[\mathrm{ft}]$

$\mathrm{kh}=$ effective permeability of net vertical formation thickness $\left[\mathrm{mD}^{*} \mathrm{ft}\right]$

In this case, under permanent pressure drawdown conditions linked with sales contract agreement it is necessary an additional effort for gas compression.

To effectively plan and design for gas well liquid loading problems, it is essential to be able to predict accurately when a particular well might begin to experience excessive liquid loading. Turner and Coleman developed correlations to predict the critical velocity assuming the droplet model (Turner). In practice, the critical velocity is generally defined as the minimum gas velocity in the production tubing required to move droplets upward. Lowering the surface pressure by compression also increases the actual gas velocity. Turner adjusted the theoretical equation for velocity upward by $20 \%$ and the equation is:

$$
V_{t}=\frac{1.59 \sigma^{\frac{1}{4}} \cdot\left(\rho-\rho_{g}\right)^{1 / 4}}{\left(\rho_{g}\right)^{1 / 2}}
$$

where $\sigma$ - surface tension [dynes/cm], $\rho$ - density $\left[\mathrm{lbm} / \mathrm{ft}^{3}\right.$ ]

Typical values of surface tension is 60 dynes $/ \mathrm{cm}$ for water and 20 dynes $/ \mathrm{cm}$ for condensate.

Although critical velocity is the controlling factor, one usually thinks of gas wells in terms of production in multiples of scf/d rather than velocity in the wellbore. Critical velocity equation is easily converted into a more useful form by computing a critical well flowrate:

Where:

$$
Q_{g}=\frac{3.067 \cdot P \cdot V_{t} \cdot A}{(T+460) \cdot Z}\left[\frac{M M s c f}{d}\right]
$$

A - Tubing cross-sectional area, $\mathrm{ft}^{2}$

$\mathrm{T}, \mathrm{P}$-surface temperature ${ }^{0} \mathrm{~F}$, surface pressure, psia

For lower surface tubing pressures, Coleman has developed similar relationships for the minimum critical flow rate for both gas and water. In essence, the formulas from Coleman are identical to Turner but without the adjustment to fit Turner's data.

Wells flowing at just below the critical velocity before compression can be increased to rates beyond the critical velocity with compression, thereby alleviating liquid-loading problems. Because the critical velocity is directly proportional to surface pressure, compression installations can be sized on the critical velocity calculation. For example, the compression station can be sized on a surface pressure that maintains the tubing production velocity at some percentage above the minimum critical velocity. With estimates of the decline of the reservoir, the installation size can be optimized to produce the most gas over the longest period.

System nodal analysis tools are ideally suited to analyse the effects of reducing the surface tubing pressure with compression because allows for the simultaneous comparison of the effects of various surface pressures on the well productivity. System nodal analysis uses single or multiple flow correlations and theoretical models developed for various components of reservoir, well completion and surface equipment systems to calculate the 
pressure loss associated with each component in the system. This information is then used to evaluate well performance under a wide conditions, which will lead to optimum single well completion and production practices, and to make the analysis of the effects of liquid loading on the gas wells. In the same time, is also used to clarify the detrimental effects of excessive surface production tubing pressure. Increased surface pressure adds back pressure on the reservoir at the sand face. The added back pressure reduces the gas production and lowers the gas velocity in the tubing, which also reduces the efficiency with which the liquids are transported to the surface.

In general, lowering the surface pressure of a well by using compression will result in more production. This is true for flowing wells and with nearly all lifted wells. Depending on the individual well, a well production can be increased over a range from only few percent to several times the current production of the well. For flowing gas wells, lowering the surface pressure can significantly increase the production, prolong the life of the well and increase reserves.

Lowering the surface pressure of a gas well has two effects both of which are beneficial for liquid loading.

- The bottomhole flowing pressure decreases, increasing production rate and gas velocity throughout the wellbore

- The required critical rate to remove liquids decreases because of the reduced pressure.

\section{Production optimization. Group compressor performance}

Brownfield field management involves a field development plan in order to explore options and targets the optimal development for individual wells. This process is performed by specialist teams who analyse, evaluate, manage and integrate multiple disciplines, subsurface and topsides complexities, uncertainties and opportunities into a single development plan for field, maximizing the overall field recovery and asset value.

Production optimization is the main objective and challenge for specialist teams and can include besides artificial lift, the subject of this paper, many other methods such as stimulation through re-perforation, wash acidizing or matrix acidizing, and fracturing operation, outlined by a surveillance program of data gathering to minimize the high level of the uncertainty of field parameters.

Starting from the main objective of rehabilitation project to increase the recovery factor, a preliminary study was performed for compression implementation in the field. After risk management was evaluated, the project team executed a pilot project of using compression in Laslau Mare field. Based on this project, in 2014 one screw compressor was installed in one of the five groups.

The incremental production has been observed during compression time and a feasibility study was conducted to evaluate the technical and economic aspects for the field by installing screw compressor in the groups. Since the feasibility study confirmed the benefits of this project, four screw compressor were installed in groups.

Any project which is carried out in a rehabilitation phase, has the main objective to increase the production, reduce the production decline and add value by running at optimal parameters. After installation, expected incremental has not been achieved due to operational field condition and other technical issues regarding the running time of compressor.

The real incremental production has been observed when the operational field condition changed in terms of field pressure. Due to lower demand for gas during warm season in Romania, the national grid pressure increased above expected or forecasted parameters, thereby an external pressure was recorded in the field. This external pressure it was also affected by turning off Filitelnic and Tigmandru Compressor Stations which are located at interference of production-transport. 
Considering this uncontrollable and unpredicted situation on the market, screwcompressor installation in the field has been shown to be a successful application.

It is observed that every 1 bar higher of field pressure, field gas production decreases around $20 \mathrm{kscm} / \mathrm{d}$ but this assumption it was no more available in 2016 when operation field condition changed. Mainly, the cause of higher field pressure is the back pressure given by national grid transportation system or because the compression station is not working at full capacity. Many calculation using system nodal analysis were made to highlight the production losses due to high field pressure. Unlike the previous case, in 2016 the following situation corresponded to production losses caused by field back pressure effects:

Table 1. Production losses/bar at high field pressure

\begin{tabular}{|c|c|}
\hline Production losses (kscm/bar) & Field pressure interval (bar) \\
\hline 28 & $7-9$ \\
\hline 28 & $9-12$ \\
\hline 33 & $12-13$ \\
\hline 38 & $13-15$ \\
\hline
\end{tabular}

To overcome the above potential losses caused by field back pressure effect, the running time of field compressor was essential. Three compressors installed in the groups shown the effective incremental in current conditions (fig.1):

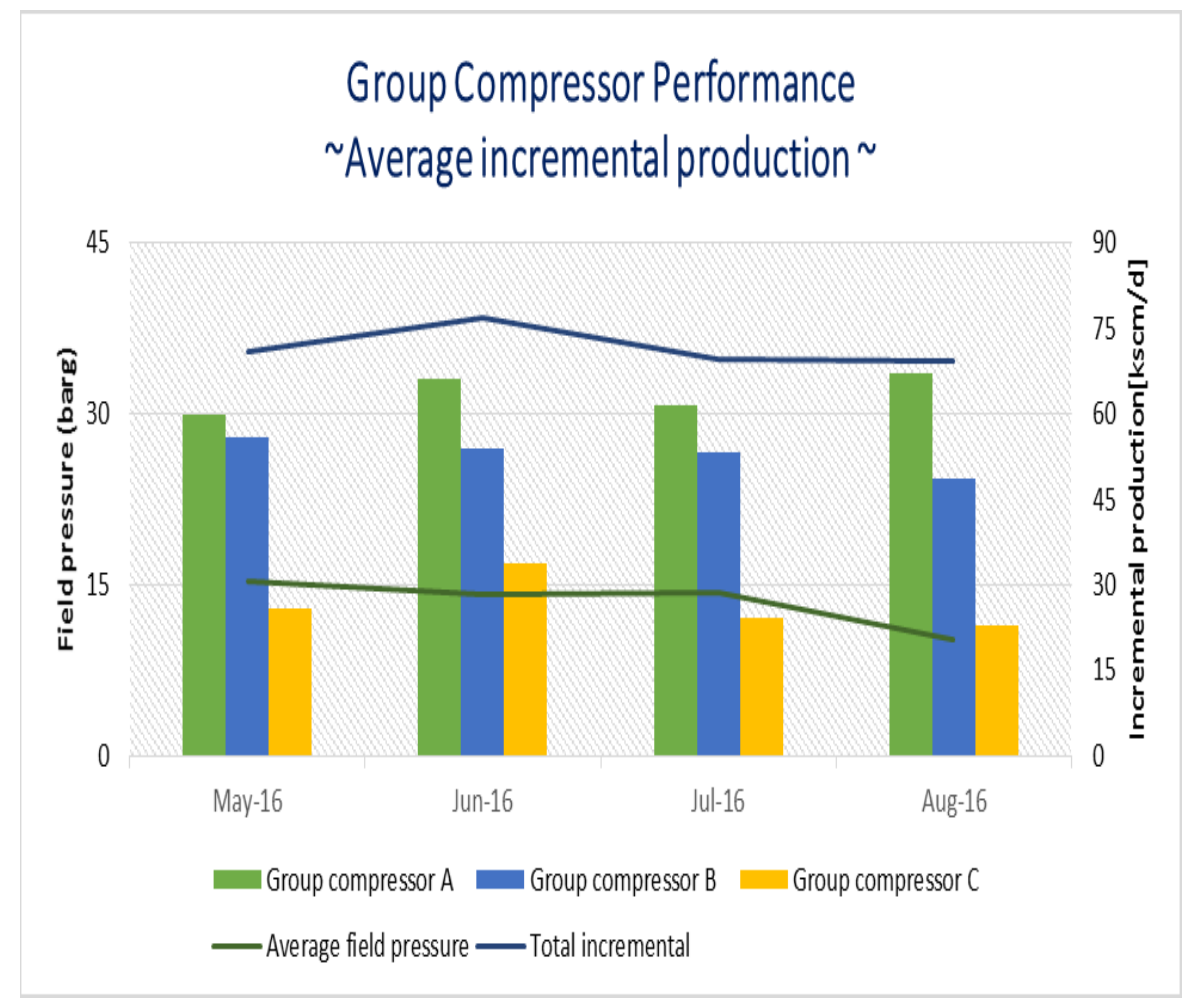

Fig. 1. Incremental production from group compressor during warm season in 2016 
The wells connected to compressors were tested previously whether are reactive to pressure changing or not.

Through nodal analysis system the well performance was simulated by using multiphase simulator PIPESIM (Schlumberger Software), in other words to get the expected incremental gas production by sensitizing the wellhead pressure values.

To calculate the incremental production for each well, the baseline was defined considering the same field operating conditions. Group compressor A had average baseline production $25.6 \mathrm{kscm} / \mathrm{d}$ with 5 wells tied in, group compressor B has 2 wells connected to it with an average baseline production of $30 \mathrm{kscm} / \mathrm{d}$ and group compressor $\mathrm{C}$ had one well connected with an average baseline production of $26.75 \mathrm{kscm} / \mathrm{d}$.

Definitely, selected wells were high reactive to pressure changes and their potential production under compression it was considered when candidate selection was done. Also, another important parameter is the maximum capacity of group compressor which is 60 $\mathrm{kscm} / \mathrm{d}$ and limits the number of well that can be connected to it.

Running parameters for group compressors presented in table below were monitored in daily basis to maintain the optimum condition for compression and prevent any failure of equipment.

Table 2. Running parameters for group compressors

\begin{tabular}{|l|l|l|l|}
\hline $\begin{array}{l}\text { Group } \\
\text { Compressor }\end{array}$ & $\begin{array}{l}\text { Suction } \\
\text { pressure (Barg) }\end{array}$ & $\begin{array}{l}\text { Discharge pressure } \\
\text { (Barg) }\end{array}$ & $\begin{array}{l}\text { Total gas compressed } \\
\text { (kscm/d) }\end{array}$ \\
\hline A & 2.2 & 18.2 & 60.7 \\
\hline B & 2.3 & 14.4 & 60.0 \\
\hline C & 3.1 & 16.2 & 55.5 \\
\hline
\end{tabular}

Figure 2 presents the well performance during warm season from each group compressor.

As we can observe in Figure 2 the well performance is directly depended on the wellhead pressure, the gas production increases when the wellhead pressure is decreases and conversely. Therefore, reducing wellhead pressure will give insignificant impact of gas production. The wellhead pressure is lower as the result of decreasing group pressure, so the gas production increases subsequently. This condition surely extends its production life cycle and improve the final gas recovery factor.

Compression at a group or field level would help to dewater multiple wells with one piece of equipment. Compression assists the well to dewater by increasing the drawdown from the reservoir. The increased drawdown translates into higher flow rates and increased gas velocities. If the drawdown is great enough the well could be able to unload itself without the assistance of afore mentioned technologies.

Compression proved to be a good option for Laslau Mare because it is not as dependent on fluid chemistry as soaping is and operates over a larger range than velocity strings do.

Group compression is advantageous in that it will assist more than one well at a time. Having multiple inlets also means that maintenance or intervention on a well will not cut off the gas supplied to the compressor, so it will be able to function continuously.

Also, from an operations standpoint no physical changes will occur at the wellhead, so operators will be able to go about their normal work without noticing any difference. 


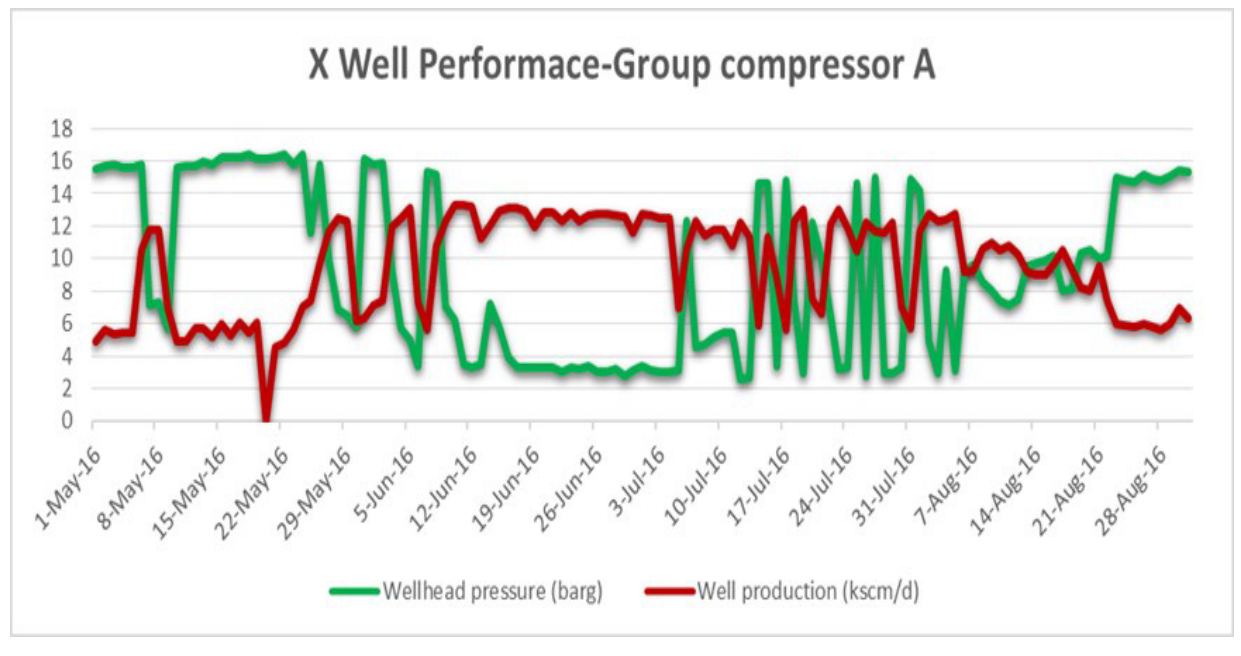

Y Well Performance-Group compressor B

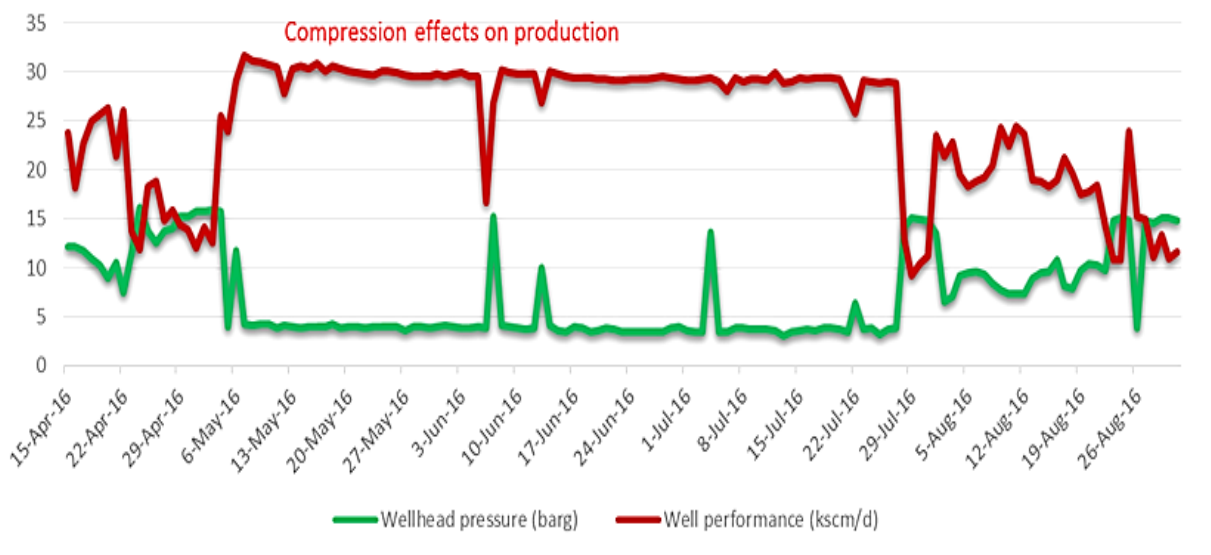

Z Well Performance- Group Compressor C

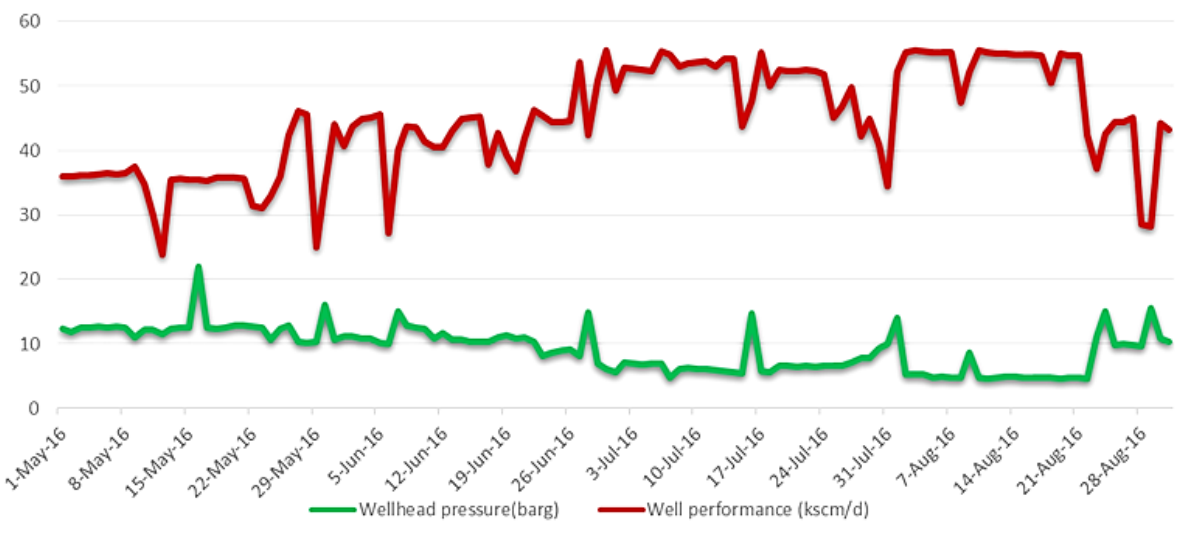

Fig. 2. Example of well performance under group compressor during warm season in 2016 


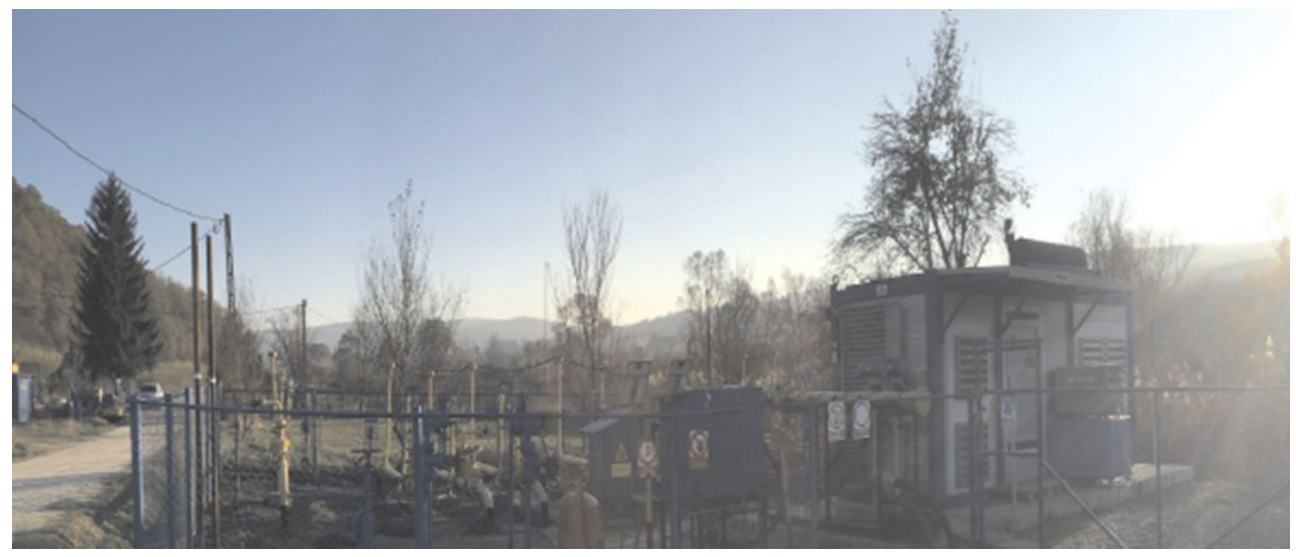

Fig. 3. Screw medium compressor installed in the group

\section{Conclusions}

Laslau Mare field, similar to others mature gas field from Transylvanian Basin, being a depleted reservoir is directly depended on external pressure from National Transport System and is having liquid loading problems. Group compressor application in the field has proved to be extremely beneficial especially when gas demanded decreases correlated with field back pressure effects.

Group compressor application can be considered a mitigation measure for field back pressure effects on the gas wells, for liquid loading problems created by external pressure and definitely to reduce the drawdown pressures.

One advantage of group compressor besides the ones mentioned, is that can compress multiple wells in the same group as long as the volume doesn't exceed $60 \mathrm{kscm} /(\mathrm{d} \cdot \mathrm{unit})$. It doesn't require changes at wellhead and the operation is uninterrupted as the unit will be standby in the group at any time. Nevertheless, disadvantages to the technology are that it requires a high capital expense. Also the equipment is rather large and will need a sizeable footprint of proper foundation. The compressor will require maintenance and consume either fuel gas during operation.

The maintenance program is very important to make sure is running in optimum conditions and the flat time is reduced.

Having the group compressor installed in a mature gas field which is running at maximum capacity, undesirable effects on wells performance created by external conditions are mitigated, production incremental is a certainty benefit, the life cycle of the field is extended, production decline is decreasing and definitely the recovery factor is increasing..

\section{References}

1. D.P Stefanescu, Introduction to the mature natural gas reservoir rehabilitation-Theory and Case studies, 375-377 (Editura Universitatii Lucian Blaga, Sibiu, 2012)

2. S.B Coleman, H.B Clay., D.G McCurdy, H.L. III Norris, Journal of Petroleum Technology 43, $329(1991)$

3. J.Lea, H.V Nickens, M.Wells, Gas Well Deliquification (Gulf Professional Publishing, 2003)

4. *** Matrix Engineering Manual-Well Performance, 119 (Schlumberger, 1998) 